\title{
Determinants of multidrug-resistant tuberculosis in patients who underwent first-line treatment in Addis Ababa: a case control study
}

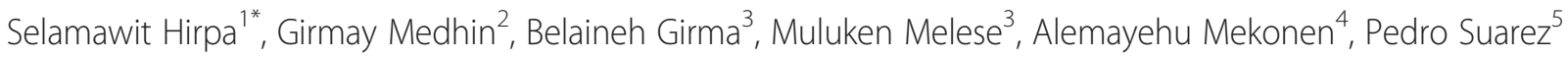
and Gobena Ameni ${ }^{1}$

\begin{abstract}
Background: Worldwide, there were 650,000 multidrug-resistant tuberculosis (MDR-TB) cases in 2010, and in 2008 the World Health Organization estimated that 150,000 deaths occurred annually due to MDR-TB. Ethiopia is $15^{\text {th }}$ among the 27 MDR-TB high-burden countries. This study identifies factors associated with the occurrence of MDR-TB in patients who underwent first-line TB treatment in Addis Ababa City.

Methods: A case control study was conducted at St. Peter Hospital and five health centers in Addis Ababa from 1 November 2011 to February 30, 2012. Cases were MDR-TB patients who were confirmed with culture and drugsusceptibility testing and were in treatment at St. Peter Hospital during the study period. Controls were patients who were on first-line anti-TB treatment and were registered as cured or having completed treatment in the period 9 April 2009- 28 February 2010, in five health centers of Addis Ababa City. Accordingly, 134 cases and an equal number of controls were included in this study. A structured interview questionnaire was used to assess factors that could potentially be associated with the occurrence of MDR-TB.

Results: Factors that were significantly associated with MDR-TB: drug side effects during first-line treatment (adjusted odds ratio (AOR): 4.5, 95\% Cl; 1.9 - 10.5); treatment not directly observed by a health worker ( $\mathrm{AOR}=11.7,95 \% \mathrm{Cl}$; 4-34.3); interruption of treatment of at least a day ( $\mathrm{AOR}=13.1,95 \% \mathrm{Cl}$ 3.0-56.6); duration of treatment between 2 and 7 months ( $\mathrm{AOR}=14.8,95 \% \mathrm{Cl}$ 2.3-96.4); and retreatment with the Category II regimen ( $\mathrm{P}=0.000)$. In the current study, HIV infection was not significantly associated with the occurrence of MDR-TB.

Conclusions: Patients who were not in strict DOTS programs and did not adhere to first-line TB treatment and patients who experienced side effects during first-line treatment and Category $\|$ retreatment were at significantly increased risk of developing MDR-TB. The DOTS program should, therefore, be strengthened to increase patient adherence. Drugsusceptibility testing is also highly recommended for all Category I treatment regimen failures before those patients begin the Category II regimen.
\end{abstract}

Keywords: TB, MDR-TB, TB treatment, TB treatment regimens, Adherence to TB treatment, TB treatment failure, DOTS

\footnotetext{
* Correspondence: Sele4jesus@gmail.com

${ }^{1}$ College of Health Sciences, Adama Science and Technology University,

P. O. Box 396, Adama, Ethiopia

Full list of author information is available at the end of the article
} 


\section{Background}

Multidrug-resistant tuberculosis (MDR-TB) is a type of TB that is resistant to at least the first line anti-TB drugs, Rifampacin and Isoniazid. MDR-TB occurs either when a person is infected with a resistant strain or when improper treatment leads to drug selection of the resistant strain [1]. When an individual who has no history of first-line TB treatment develops MDR-TB, it is termed primary. When insufficient treatment leads to selection of spontaneously resistant strains (i.e., drug resistance is acquired), the disease is termed secondary MDR-TB [2].

Worldwide, there were 650,000 MDR-TB cases in 2010, and in 2008 World Health Organization (WHO) estimated that there were 150,000 deaths annually due to MDR-TB [3]. Overall, the 27 high MDR-TB burden countries accounted for $85 \%$ of all MDR-TB cases. China, and India, was the top two countries accounting 50\% MDR-TB cases [3]. A 2010 WHO report showed that the number of MDR-TB cases is rising in Africa [1]. Ethiopia is $15^{\text {th }}$ among the 27 MDR-TB high-burden countries, with an estimated 5,200 cases occurring each year [4].

The occurrence of MDR- TB is mainly attributable to human error, although genetic factors are also believed to contribute to a certain extent [5]. The principal patient-related factor that predicts the occurrence of MDR-TB is non-adherence to treatment [6]. The firstline anti-TB drugs used in Ethiopia in 2009/2010 were rifampicin $(\mathrm{R})$, ethambutol $(\mathrm{E})$, isoniazid $(\mathrm{H})$, and pyrazinamide $(\mathrm{Z})$ [7]. The category II treatment regimen (S (ERHZ) for two months, ERHZ for one month and $\mathrm{E}(\mathrm{RH})$ for five months three times a week), which adds streptomycin to the category I regimen (ERHZ for two months and RH for four months) has been blamed for increasing the risk of developing MDR-TB [8], despite the fact that patients have already been exposed to most of the drugs.

The emergence of MDR-TB is a threat for the populations of resource-limited countries. In Ethiopia, the low socioeconomic status of the people, high prevalence of infectious diseases and limited access to well-equipped health care facilities worsens the effect of MDR-TB. Furthermore, poor treatment outcomes, longer treatment time (about two years), higher treatment costs, and many more complications make MDR-TB a more complex disease than TB $[1,9]$. In 2010, less than $5 \%$ of new and previously treated $\mathrm{TB}$ patients were tested for MDR-TB because of limited availability of the test in most developing countries [10]. For example in Ethiopia, in 2010 the ratio of laboratories capable of performing mycobacterial culture was 0.1 per 5 million populations [10]. Similarly, the ratio of laboratories capable of running line probe assays (LPA) for rapid detection of MDR-TB was 0.1 per 5 million populations [10]. At the time of this study in Ethiopia, the LPA, or culture using Lőwenstein-Jensen media (LJ), and drug-susceptibility testing (DST) were provided only at the Ethiopian Health Nutrition and Research Institute (EHNRI) in Addis Ababa.

MDR-TB occurs mostly in relation to improper treatment of drug-susceptible TB. In countries like Ethiopia MDR-TB is becoming a challenge because of poor adherence to treatment and an increase in the use of illegal and unapproved treatment regimens for MDR-TB [9]. To make things worse, in these TB and MDR-TB highburden countries patients stay in their communities for longer periods without being diagnosed or getting proper treatment. Even after diagnosis, because there are few diagnostic and treatment facilities and a lack of trained health professionals and drugs, patients do not start treatment immediately. This delay potentially allows easy spread of the disease to a large number of individuals within a short time. The aim of this study is to asses factors that determine the occurrence MDR-TB among patients who had taken first line anti-TB treatment in Addis Ababa City.

\section{Methods}

\section{Study area and study design}

This health institution-based case control study was conducted between 1 November 2011 and 28 February 2012 in Addis Ababa, the capital city of Ethiopia. The estimated population size of Addis Ababa is 2.74 million and the male population constitutes $48 \%$ [11]. Administratively, the city is divided into 10 sub-cities and further classified into 99 kebeles (lowest government administrative unit). The health institutions in the city includes 47 hospitals, 204 private higher clinics, 226 private midlevel clinics (known as medium clinics), 143 private lower clinics, and 37 government health centers [Addis Ababa Health Bureau report].

\section{Study setting}

Cases were selected from St. Peter Hospital, one of the two MDR-TB patient treatment centers in Addis Ababa, and controls were selected from Addis Ketema Health Center in Addis Ketema sub-city; Woreda 9 Health Centers in Kolfe Keranyo sub-city; Lideta Health Center in Lideta sub-city; Kasanches Health Center in Kirkos subcity; and Woreda 19 and Nifas Silk Lafto health centers in Nifas Silk Lafto sub-city.

\section{Eligibility of study participants}

MDR-TB patients diagnosed by LPA, or culture using LJ, and DST at the EHNRI and who were being treated at St. Peter Hospital during the study period were considered as cases. In Ethiopia a patient is a suspect for MDR-TB if he/she is a symptomatic close contact of a 
confirmed MDR-TB patient; a symptomatic individual from a known high-risk group such as health workers; a case of treatment failure; a new TB patient who remains smear positive after 2 months of treatment (for new cases) and after 3 months of retreatment with first-line treatment or retreatment (e.g., return after default, relapse) [12]. The controls were patients who had completed first-line anti-TB treatment and were declared cured or treatment completed using the WHO criteria and adopted by FMOH of treatment outcomes [13] between 9 April 2009 and 28 February 2010. Additionally, the controls were those with no clinical symptoms of TB based on the WHO criteria.

\section{Recruitment of study participants}

During the study period there were 147 eligible confirmed MDR-TB cases at St. Peter Hospital, 134 of who consented to participate in the study. These patients were residents of Addis Ababa who had a history of taking their first course of first-line TB treatment and were on MDR-TB treatment during the period of data collection. Prior to identification of the controls, five health facilities were identified based on the number of MDR-TB cases that they referred to St. Peter Hospital. The same number of controls was selected from each of these five health facilities. The sampling frame comprised all patients who had completed first-line anti-TB treatment and were registered as cured or treatment completed. Following this, the required sample size of the control group was selected using systematic random sampling. When a selected patient declined to participate in the study, the next person in the register was taken.

The contact information of controls and cases was obtained from the health center's TB clinic patient registration book. The selected individuals were contacted by telephone and given information about the study. Individuals who were willing to participate and gave verbal consent were scheduled for an interview at the health facility.

\section{Data collection}

A structured questionnaire was used to collect information from study participants. Secondary data were collected from TB and MDR-TB registers. Patient charts and the data collection format were used to determine and record their initial TB episode. The FMOH screening tool was used to identify controls free of suspected TB at the time of the study [7]. Day-long training was provided to the nurses and health officers involved in the data collection process. The main variables included in study instrument were sex, age, socioeconomic status, ethnicity, HIV status, adherence or non-adherence to the first course of anti-TB treatment, number of previous anti-TB treatments, treatment with the Category II regimen, ever- interruption in taking medicine for a day, and occurrence of drug side effects during the first course of TB treatment.

\section{Data management and analysis}

Data were entered using Epidata version 3.1 and exported to STATA version 11 for analysis. Data completeness and consistency were checked by running frequencies of each variable. Bivariate analyses were carried out for categorical variables, and odds ratios were used to quantify the strength of association between potential risk factors and MDR-TB. Multiple logistic regressions were used to control the confounding effect of different variables while assessing the effect of each variable on the likelihood of MDR-TB occurrence. A p-value of 0.05 was used as the cut-off point for statistical significance. Variables having a p-value of at most 0.05 in bivariate analysis were included in the multivariate logistic regression model. In multivariate logistic regression, the adjusted effects of three variables (the number of pulmonary TB episodes, ever-interruption in anti-TB treatment for at least a day in the first course, and duration of the first course of TB treatment) were estimated without concurrently adjusting for each other to avoid multicollinearity.

\section{Ethical considerations}

Ethical clearance was obtained from the institutional review board of the Aklilu Lemma Institute of Pathobiology at Addis Ababa University and St. Peter Hospital. Written permission to conduct the study was also obtained from the managers of each health facility. A statement about the purpose of the study was read to each study participant, and those who gave verbal consent to participate in the study were interviewed. Study participants were interviewed privately, and their names were not written on the questionnaire to ensure confidentiality.

\section{Results}

Sociodemographic characteristics of study participants

A total of 134 cases and an equal number of controls were included in the study. A total of 81 (60.5\%) of the MDR-TB cases were males, but females represented the majority in the control group (70 females, or 52.5\%). Single or divorced individuals accounted for the majority 101 (75.3\%) of the MDR-TB cases but only about half (69, or $51.5 \%$ ) in the control group (Table 1). The mean age was $25.1(\mathrm{SD}=10.94)$ years for MDR-TB cases and $30.72(\mathrm{SD}=11.4)$ years for controls.

\section{TB-related conditions}

Table 2 summarizes TB-related conditions in the cases and controls. Of the 134 MDR-TB cases, 96 (71.6\%) had had two or more episodes of TB treatment before they 
Table 1 Sociodemographic characteristics of MDR-TB cases and their controls in Addis Ababa, 2011

\begin{tabular}{|c|c|c|c|c|}
\hline \multirow{3}{*}{$\begin{array}{l}\text { Characteristics } \\
\text { (variables) }\end{array}$} & \multicolumn{2}{|l|}{ Cases } & \multicolumn{2}{|l|}{ Controls } \\
\hline & \multicolumn{2}{|l|}{$(n=134)$} & \multicolumn{2}{|l|}{$(n=134)$} \\
\hline & Number & Percentage & Number & Percentage \\
\hline \multicolumn{5}{|l|}{ Sex } \\
\hline Male & 81 & 60.5 & 64 & 47.5 \\
\hline Female & 53 & 39.5 & 70 & 52.5 \\
\hline
\end{tabular}

Age at the time of first anti-TB treatment (years)

$\begin{array}{lllll}5-25 & 85 & 63.4 & 47 & 35.1 \\ 26-45 & 40 & 29.9 & 70 & 52.2 \\ 46-72 & 9 & 6.7 & 17 & 12.7\end{array}$

Marital status

$\begin{array}{lllll}\text { Single } & 85 & 63.4 & 60 & 44.8 \\ \text { Married } & 32 & 23.8 & 56 & 41.8 \\ \text { Divorced } & 16 & 11.9 & 9 & 6.7 \\ \text { Widow/widower } & 1 & 0.75 & 9 & 6.7\end{array}$

\section{Educational status}

Up to fourth grade

Completed

$5^{\text {th }}-8^{\text {th }}$ grade

Completed

$8^{\text {th }}-10^{\text {th }}$ grade

Above $10^{\text {th }}$ grade

Occupation

No work

Student

Daily laborer

Government worker

Private worker 31

Businessman

$$
15
$$

\section{2}

11.9

20.1

56.7

64

47.8

Number of rooms in residence

$\begin{array}{lllll}1 & 61 & 45.5 & 37 & 27.6 \\ 2-3 & 57 & 42.5 & 63 & 47 \\ 4-5 & 11 & 8.2 & 34 & 25.4 \\ 6-9 & 5 & 3.7 & 0 & 0\end{array}$

Family size

\begin{tabular}{lllll}
$1-3$ & 57 & 42.5 & 49 & 36.6 \\
$4-6$ & 57 & 42.5 & 70 & 52.2 \\
$7-11$ & 20 & 15 & 15 & 11.2 \\
\hline
\end{tabular}

were diagnosed as MDR-TB, and $9(6.7 \%)$ of the cases had had four or more episodes of TB. In the control group, only $14(10.4 \%)$ had undergone two rounds of TB treatment, and one case had suffered four or more episodes of TB. HIV positivity was significantly lower in the MDR-TB cases than in the control group (13.4\% versus $29.9 \%$; p-value $<0.001)$. The quality of care provided by
Table 2 Tuberculosis disease-related conditions in each category (case/control) in Addis Ababa, 2011

\begin{tabular}{llll}
\hline Characteristics & Cases & & Controls \\
& & & $(\mathrm{n}=134)$ \\
& Number Percentage & & Number Percentage
\end{tabular}

No. of pulmonary TB episodes

$\begin{array}{lllll}\text { One } & 29 & 21.6 & 119 & 88.8 \\ \text { Two } & 66 & 49.3 & 14 & 10.5 \\ \text { Three } & 30 & 22.4 & 0 & 0 \\ \text { Four or more } & 9 & 6.7 & 1 & 0.75\end{array}$

HIV status

$\begin{array}{lllll}\text { Negative } & 116 & 86.6 & 94 & 70.2\end{array}$

$\begin{array}{lllll}\text { Positive } & 18 & 13.4 & 40 & 29.9\end{array}$

Ever lived with MDR-TB patient

$\begin{array}{lllll}\text { No } & 122 & 91.0 & 134 & 100 \\ \text { Yes } & 12 & 9.0 & 0 & 0\end{array}$

Site of TB infection during first episode

$\begin{array}{lllll}\text { Pulmonary } & 130 & 97 & 90 & 67.2 \\ \text { Extrapulmonary } & 4 & 3.0 & 44 & 32.8\end{array}$

Smear-positive during first anti-TB treatment

$\begin{array}{lllll}\text { No } & 11 & 8.2 & 82 & 61.2 \\ \text { Yes } & 123 & 91.8 & 52 & 38.8\end{array}$

Ever counseled by health worker

$\begin{array}{lllll}\text { No } & 44 & 32.8 & 1 & 0.75 \\ \text { Yes } & 90 & 67.2 & 133 & 99.25\end{array}$

Presence of other disease

$\begin{array}{lllll}\text { No } & 111 & 82.8 & 115 & 85.5\end{array}$

Ever smoked cigarettes

$\begin{array}{lllll}\text { No } & 125 & 93.3 & 115 & 85.8\end{array}$

$\begin{array}{lllll}\text { Yes } & 9 & 6.7 & 19 & 14.2\end{array}$

Perception about the care provided

$\begin{array}{lllll}\text { Very good } & 5 & 3.7 & 87 & 64.9 \\ \text { Good } & 13 & 9.7 & 36 & 26.9 \\ \text { Satisfactory } & 77 & 55.5 & 8 & 6.0 \\ \text { Poor } & 39 & 29.1 & 3 & 2.2\end{array}$

Weight measured by health worker before starting treatment

\begin{tabular}{lllll} 
No & 3 & 2.2 & 0 & 0 \\
Yes & 120 & 89.6 & 134 & 100 \\
Doesn't remember & 11 & 8.2 & 0 & 0 \\
\hline
\end{tabular}

health care providers was perceived as poor by $39(29.1 \%)$ of MDR-TB cases and by 3 (2.2\%) of the controls.

\section{Treatment-related conditions}

Conditions related to anti-TB treatment are summarized in Table 3. During first-line anti-TB treatment, drug side 
Table 3 First-line tuberculosis treatment-related conditions in MDR-TB cases and their controls in Addis Ababa, 2011

\begin{tabular}{|c|c|c|}
\hline \multirow{3}{*}{ Characteristics } & Cases & Controls \\
\hline & $(n=134)$ & $(n=134)$ \\
\hline & Number Percentage & Number Percentage \\
\hline
\end{tabular}

Encountered drug side effect

$\begin{array}{lllll}\text { No } & 67 & 50.0 & 109 & 81.3 \\ \text { Yes } & 67 & 50.0 & 25 & 18.7\end{array}$

Suffered the most common drug side effect (vomiting)

$\begin{array}{lllll}\text { No } & 85 & 63.4 & 124 & 92.5 \\ \text { Yes } & 49 & 36.6 & 10 & 7.5\end{array}$

Duration of first-time TB treatment

$\begin{array}{lllll}2-4 \text { months } & 3 & 2.2 \% & 1 & 0.75 \% \\ 5-7 \text { months } & 22 & 16.4 \% & 2 & 1.5 \% \\ 8 \text { months } & 103 & 76.9 \% & 128 & 95.5 \\ 9-13 \text { months } & 6 & 4.5 \% & 3 & 2.2 \%\end{array}$

Directly observed by health worker while taking anti-TB

$\begin{array}{lllll}\text { No } & 65 & 48.5 & 7 & 5.2\end{array}$

$\begin{array}{lllll}\text { Yes } & 69 & 51.5 & 127 & 94.8\end{array}$

If yes, how many months

$\begin{array}{lllll}1-2 \text { weeks } & 11 & 15.95 & 0 & 0 \\ \text { One month } & 32 & 46.4 & 1 & 0.8 \\ \text { Two months } & 26 & 37.7 & 126 & 99.2\end{array}$

Reason for interruption for at least a day

$\begin{array}{lllll}\text { Side effects } & 34 & 36.6 & 3 & 30.0 \\ \text { Forgot to take it } & 23 & 24.7 & 7 & 70.0 \\ \begin{array}{l}\text { Symptoms were gone } \\ \text { and felt good }\end{array} & 29 & 31.2 & 0 & 0 \\ \begin{array}{l}\text { Shortage of drug } \\ \text { Ever interrupted anti-TB for at least a day }\end{array} & 7 & 7.5 & 0 & 0 \\ \begin{array}{l}\text { No } \\ \text { Ne }\end{array} & 30.6 & 124 & 92.5 \\ \text { Yes } & 93 & 69.4 & 10 & 7.5 \\ \text { Took the medication at a regular time } & & \\ \text { No } & 81 & 60.5 & 25 & 18.7 \\ \text { Yes } & 53 & 39.5 & 109 & 81.3\end{array}$

Outcome of first anti-TB treatment

\begin{tabular}{lccll} 
Treatment success & 64 & 47.7 & 132 & 98.5 \\
Defaulted & 16 & 11.9 & 2 & 1.5 \\
Treatment failure & 54 & 40.3 & 0 & 0 \\
\multicolumn{5}{l}{ Drug regimen (category) for the second time } \\
$\begin{array}{l}\text { Category II } \\
\text { Category I }\end{array}$ & 101 & 94.4 & 3 & 23.1 \\
\hline
\end{tabular}

effects were encountered in 60 (50\%) of the MDR-TB cases and 25 (18.7\%) of the controls. Among the current MDR-TB patients, their first-line anti-TB treatment was directly observed by health workers in only 69 cases
(51.5\%), while 127 (94.8\%) of the controls were treated in accordance with the strict DOTS guidelines of the country. First-line anti-TB treatment was interrupted for at least a day in $93(69.4 \%)$ of the MDR-TB cases, and in only $10(7.5 \%)$ of the controls. Out of the 16 MDR-TB patients who were poor adherers of treatment in category I treatment $10(62.5 \%)$ were male. Reasons for interruption among MDR-TB cases were drug side effects in 34 cases (36.6\%), followed by improved/disappeared symptoms and the perception that TB was cured 29 cases $(31.2 \%)$, and forgetfulness about taking the medicine 23 cases (24.7\%). Duration of first-line anti-TB treatment was exactly 8 months in 103 (76.9\%) of the MDR-TB cases and 128 (95.5\%) of the controls. Among the MDR-TB cases, the outcomes of the first course of anti-TB treatment was reported as treatment success in 64 cases (47.7\%), defaulter in 16 cases (11.9\%), and treatment failure in 54 cases $(40.3 \%)$. In the controls, $132(98.5 \%)$ were declared treatment successes. Of the MDR-TB cases, 107 (79.9\%), and 13 (9.7\%) of the controls, were treated at least twice with first-line antiTB treatment. Of the 107 current MDR-TB cases, 101 (94.4\%) were also treated with the Category II regimen, while only $3(23.1 \%)$ of the 13 controls were treated with the Category II regimen.

\section{Results from logistic regression analysis}

After adjusting for possible confounding factors (Table 4), the study found that MDR-TB development is significantly associated with two or more episodes of TB illness (AOR = 31.8; 95\% CI; 8.7-115.5), interruption of first-line anti-TB treatment for at least a day $(\mathrm{AOR}=13.1 ; 95 \% \mathrm{CI} ; 3.0$ 56.6), education above 10 th grade $(\mathrm{AOR}=3.7 ; 95 \% \mathrm{CI}$; 1.1-12.1), and male sex (AOR $=2.7 ; 95 \% \mathrm{CI} ; 1.1-6.5)$.

The number of rooms in the patient's household also showed a significant association with MDR-TB (AOR = 10.1; 95\% CI; 2.0-49.4). Pulmonary TB (AOR = 10.9; 95\% CI; 2.8-41.9), drug side effects during first-line treatment $(\mathrm{AOR}=4.5 ; 95 \% \mathrm{CI} ; 1.9-10.5)$, lack of direct observation by health workers $(\mathrm{AOR}=11.7 ; 95 \% \mathrm{CI}$; 4.0-34.3), and less than 7 months of first-line anti-TB treatment $(\mathrm{AOR}=14.895 \% \mathrm{CI}$; 2.3-96.4) were also significantly associated with MDR-TB development. Fischer's exact test showed that being treated with the Category II regimen was associated with MDR-TB development $(\mathrm{P}=0.000)$.

HIV status, history of smoking, experience of drug shortages, and family size were not significantly associated with MDR-TB development.

\section{Discussion}

A case control study with equal number of cases and controls was conducted by recruiting a total of 268 study participants to determine factors associated with developing 
Table 4 Determinants of multidrug-resistant tuberculosis from logistic regression model

\begin{tabular}{lllll}
\hline Characteristics & Case & Control & Crude OR & Adjusted OR \\
& Number & Number & $(95 \% \mathrm{Cl})$ & $(95 \% \mathrm{Cl})$ \\
\hline
\end{tabular}

Individually adjusted for the remaining variables

Number of pulmonary TB episodes

$\begin{array}{lllll}\text { One } & 29 & 119 & 1 & 1 \\ \text { Two or more } & 105 & 15 & 28.7(14.6-56.5) & 31.8(8.7-115.5)\end{array}$

Ever interrupted anti-TB for at least a day

$\begin{array}{lllll}\text { No } & 41 & 124 & 1 & 1 \\ \text { Yes } & 93 & 10 & 28.1(13.4-58.1) & 13.1(3.0-56.6)\end{array}$

Duration of first course of TB treatment (months)

$\begin{array}{lllll}2-7 & 25 & 3 & 10.0(2.9-34.1) & 14.8(2.3-96.4) \\ \geq 8 & 109 & 131 & 1 & 1\end{array}$

Adjusted for all variables

Age when taking first-line anti-TB for the first time (years)

$\begin{array}{lllll}46-72 & 9 & 17 & 1 & 1 \\ 26-45 & 40 & 70 & 1.1(0.4-2.6) & 1.4(0.3-5.8) \\ 5-25 & 85 & 47 & 3.4(1.4-8.3) & 4.6(1.1-20.5)\end{array}$

Marital status

$\begin{array}{lllll}\text { Single } & 85 & 60 & 2.5(1.4-4.3) & 1.2(0.5-3.3) \\ \text { Married } & 32 & 56 & 1 & 1 \\ \text { Divorced/ } & 17 & 1 & 1.7(0.75-3.7) & 3.1(0.7-13.2)\end{array}$

separated

\section{Educational status}

$\begin{array}{lcccc}\begin{array}{l}\text { Up to fourth } \\ \text { grade }\end{array} & 15 & 24 & 1 & 1 \\ \begin{array}{l}\text { Completed } \\ 5^{\text {th }}-8^{\text {th }} \text { grade }\end{array} & 16 & 20 & 1.3(0.5-3.2) & 1.2(0.3-5.1) \\ \begin{array}{l}\text { Completed } \\ 8^{\text {th }}-10^{\text {th }} \text { grade }\end{array} & 27 & 25 & 1.7(0.7-4.0) & 1.4(0.4-5.1) \\ \begin{array}{l}\text { Above } 10^{\text {th }} \\ \text { Srade }\end{array} & 76 & 64 & 1.9(0.9-3.9) & 3.7(1.1-12.1) \\ \begin{array}{l}\text { Female } \\ \text { Male }\end{array} & 53 & 70 & 1 & 1 \\ \text { Num } & 81 & 64 & 1.7(1.0-2.7) & 2.7(1.1-6.5)\end{array}$

Number of rooms in residence

$\begin{array}{lllll}4-9 & 16 & 34 & 1 & 1 \\ 2-3 & 57 & 63 & 1.9(1.0-3.9) & 3.3(1.0-10.9) \\ 1 & 61 & 37 & 3.5(1.7-7.2) & 10.1(2.0-49.4)\end{array}$

Number of rooms in residence

$\begin{array}{lllll}4-9 & 16 & 34 & 1 & 1 \\ 2-3 & 57 & 63 & 1.9(1.0-3.9) & 3.3(1.0-10.9) \\ 1 & 61 & 37 & 3.5(1.7-7.2) & 10.1(2.0-49.4)\end{array}$

Family size

$\begin{array}{lllll}1-3 & 57 & 49 & 1 & 1 \\ 4-6 & 57 & 70 & 0.7(0.4-1.2) & 1.6(0.5-5.0) \\ 7-11 & 20 & 15 & 1.2(0.5-2.5) & 2.9(0.7-13.0)\end{array}$

Table 4 Determinants of multidrug-resistant tuberculosis from logistic regression model (Continued)

\begin{tabular}{lllll}
\hline HIV status & & & & \\
Negative & 116 & 94 & $2.7(1.5-5.1)$ & $2.8(0.9-8.5)$ \\
Positive & 18 & 40 & 1 & 1
\end{tabular}

Site of TB infection during first episode

$\begin{array}{lllll}\text { Extrapulmonary } & 4 & 44 & 1 & 1 \\ \text { Pulmonary } & 130 & 90 & 15.9(5.5-45.8) & 10.9(2.8-41.9)\end{array}$

Encountered drug side effect

$\begin{array}{lllll}\text { No } & 67 & 109 & 1 & 1 \\ \text { Yes } & 67 & 25 & 4.4(2.5-7.6) & 4.5(1.9-10.5)\end{array}$

Encountered shortage of drug

$\begin{array}{lllll}\text { No } & 106 & 124 & 1 & 1 \\ \text { Yes } & 28 & 10 & 3.3(1.5-7.1) & 2.7(0.8-9.5)\end{array}$

Directly observed by health worker while taking anti-TB

$\begin{array}{lllll}\text { Yes } & 69 & 127 & 1 & 1 \\ \text { No } & 65 & 7 & 17.1(7.4-39.3) & 11.7(4.0-34.3)\end{array}$

Took the medication at a regular time

$\begin{array}{lllll}\text { No } & 69 & 127 & 1 & 1 \\ \text { Yes } & 65 & 7 & 17.1(7.4-39.3) & 11.7(4.0-34.3)\end{array}$

Ever smoked cigarettes

\begin{tabular}{lllll} 
No & 125 & 115 & 1 & 1 \\
Yes & 9 & 19 & $0.4(0.19-1.0)$ & $0.4(0.1-1.8)$ \\
\hline
\end{tabular}

MDR-TB after taking first line anti-TB treatment. Factors which were associated with MDR-TB: the first site of TB infection being pulmonary, encountering drug side effects during the first course of treatment, having more than one TB episode, undergoing the Category II regimen, and taking anti-TB treatment for less than 7 months.

The study also found that being male was a risk factor for MDR-TB development. A study in Nigeria showed that being male was a risk factor for defaulting from anti-TB medication [14]. Similarly, this study showed that among MDR-TB cases who were defaulters in their first-line TB treatment, $62.5 \%$ were males. The association between being male and having MDR-TB could be due to the fact that males have a higher tendency not to adhere to anti-TB treatment than females, thus increasing their risk of developing MDR-TB. Another study showed that individuals who do not take anti-TB medication regularly have increased risk for MDR-TB [15]. Our study also showed that individuals who did not take first-line anti-TB drugs regularly had increased risk for development of MDR-TB.

Evidence from a previous study has shown that poor treatment adherence was a risk factor for MDR-TB [8]. The current study also showed that individuals who took first-line anti-TB treatment for duration of 2 to 7 months 
had increased risk of developing MDR-TB. In Ethiopia, the previous guideline for first-line anti-TB treatment was 8 months' duration, but the standard has been changed to 6 months. TB therapy requires more than $90 \%$ adherence to facilitate cure [16], and 2 to 7 months $(25 \%-87.5 \%$ of the prescribed duration) is less than the required duration to result in cure.

Additionally, individuals who were not under strict DOTS per national guidelines during their first anti-TB treatment had an 11.7 times increased risk for MDR-TB. An analysis that used empirical data to determine the impact of the expansion of the DOTS strategy on TB case finding and treatment success found that countries with full DOTS coverage had at least an $18 \%$ increase in the treatment success rate [17]. An individual who is supervised by a health worker is more likely to take the appropriate dose of medicine and less likely to miss a treatment. Furthermore, individuals who come for DOTS have frequent contact with health workers and thus have increased opportunities to get advice and counseling, which might help them to adhere to medication protocol.

As expected, individuals who encountered drug side effects during the first course of TB treatment had a 4.5 times increased risk of developing MDR-TB. Studies done in three districts of Arsi Zone, Ethiopia, found that anti-TB drug side effects were significantly associated with a high rate of defaulting [18]. When patients develop side effects, they tend to stop treatment, which favors the development of MDR-TB. If the DOTS strategy of the nation were followed in all cases, there would be a chance to counsel patients and even treat adverse drug reactions before treatment interruption. In our study, the first-line anti-TB treatment of $48.5 \%$ of the MDR-TB cases was not directly observed. A systematic review of 29 published reports on risk factors associated with MDR-TB in Europe revealed that previous treatment was the strongest determinant of MDR-TB and that the pooled risk of MDR-TB was 10.23 times higher in previously treated than in never-treated cases [19]. A study in Uganda also showed that multiple TB episodes and treatment failure were significantly associated with MDR-TB [20]. Similarly, in Ethiopia, according to a nationwide anti-TB drug resistance survey conducted in $2005,1.6 \%$ of newly diagnosed TB cases were infected with MDR-TB, while $11.8 \%$ of the MDR-TB cases were previously treated TB cases [10].

One can see how MDR-TB is prevalent in individuals who have a history of treatment compared to new patients. Similarly, the current study showed that having more than one TB episode also increased risk for MDRTB. This may be related to the previous treatment outcome, default, treatment failure, or relapse, or the patient may have had MDR-TB initially.
Having pulmonary TB during first anti-TB treatment was associated with increased risk for MDR-TB. This may also be associated with the fact that smear-positive pulmonary TB individuals have a high bacterial load and may not respond to the treatment within a short period of time, as do those with a low bacterial load [21]. For this reason, smear-positive pulmonary TB patients might be more prone to develop MDR-TB. The other explanation might be associated with diagnostic difficulties. In case of extra pulmonary MDR- TB the bacterial load is lower and difficult for definite diagnosis comparing to pulmonary MDR-TB. Limited capacity of the existing laboratory facilities especially for the diagnosis of extra pulmonary MDR-TB might explain the association of being Pulmonary TB and having MDR-TB.

This study showed that individuals who were treated by the Category II regimen had increased risk for MDRTB. More than one explanation may be given for the association of Category II treatment and MDR-TB. These individuals might have had a previous TB treatment history and registered for the treatment as treatment failures, defaulters, or relapse cases, or they might have already had MDR-TB at the initiation of the Category II regimen. Another explanation is that adding one drug in the failing regimen could change susceptible strains and lead to multidrug resistance. "Michael Iseman, the USbased MDR-TB specialist, had 10 commandments for the physicians not to change fully drug susceptible organisms to MDR-TB; the first one was never to add a single drug to a failing regimen and the other nine were to repeat the first commandment to make sure it was well understood" [8]. WHO recommends that DST should be done for all previously treated patients before they are treated with the Category II drug regimen, and in conditions where DST is not available, the Category II regimen can be used for relapse, default, and treatment failure for low- or medium-MDR-TB-burden countries [9]. A cross-sectional study in South Africa showed that retreatment patients had increased risk for any drug resistance and MDR-TB [22]. Having a DST before embarking on the Category II regimen is very important. In Ethiopia, because of low laboratory capacity, performing DST for all previously treated patients is difficult even though the country is one of the high-MDR-TB- burden countries. An individual's treatment may fail because they have already had MDR-TB or because drug resistance was caused by the retreatment regimen [23]. This is because the patient has already taken all the drugs in the Category II regimen in the previous treatment, except streptomycin, which is the oldest drug.

In the current study, HIV status had no significant association with MDR-TB. A study in Thailand showed also that HIV status was not significantly associated with MDR-TB [23]. In France, being HIV positive was 
associated with primary MDR-TB but it was not associated with secondary MDR-TB [24]. A cross-sectional study in South Africa showed that in retreated patients, HIV had no significant association with MDR-TB [25]. The study participants in the current study were patients who had a history of first-line anti-TB treatment. It is possible that the result could have been different if all study participants were primary MDR-TB cases rather than MDR-TB cases who had a history of previous treatment. A study in Ukraine showed that HIV-positive individuals had a $50 \%$ higher risk of developing MDR-TB at their first TB infection [26]. This is because being HIV positive is one risk factor for drug-susceptible $\mathrm{TB}$, which is related to immune system suppression. Being HIV positive might carry the same risk of infection with MDR-TB but may not contribute to the change of a drug-susceptible strain of TB to MDR-TB.

The strengths of the current study are that study participants in the control group finished first-line anti-TB treatment two years before the study period, which reduced the chance of relapse. They were selected from the five health facilities in Addis Ababa that reported the most MDR-TB cases to St. Peter Hospital, so that cases and controls would have a better likelihood of coming from similar backgrounds and be most likely to receive the same service. Regarding the case group, all cases that fulfilled the eligibility criteria that were available during the study period and willing to respond were included in the study. This was helpful to decrease sampling error.

The current study is not without limitations, however. Recall bias could be considered one potential challenge, since some of the information was based on the recall of the study participants. Furthermore, it was not clear whether all cases had MDR-TB before or after undergoing first-line TB treatment, since DST was not done before they took first-line TB treatment or Category II regimens.

\section{Conclusions}

Non-adherence to the first line anti-TB treatment was significantly associated with MDR-TB. Taking medication without interruption, taking medication regularly, and having supervision (DOTS) had a protective effect against MDR-TB. Having more than one pulmonary TB episode had a significant association with MDR-TB. Individuals who were treated with the Category II regimen were also found to have an increased risk for MDR-TB. HIV status was not significantly associated with MDRTB among individuals who had been previously treated with first-line anti-TB drugs. Hence, strengthening DOTS programs to enhance patient adherence to anti$\mathrm{TB}$ treatment and giving special attention to individuals at high risk for MDR-TB and prioritizing them for DST are recommended.

\section{Abbreviations}

AFB: Acid fast bacilli; AOR: Adjusted odds ratio; Cl: Confidence interval; DOTS: Directly observed treatment short course; DST: Drug sensitivity test; EHNRI: Ethiopia health nutrition and research institute; FMOH: Federal Ministry of Health; HBC: High burden country; HIV: Human immune deficiency virus; IRB: Institutional Ethical Review Board; MDR-TB: Multi drug resistant tuberculosis; OR: Odds ratio; PI: Principal investigator;

TB: Tuberculosis; WHO: World Health Organization; XDR-TB: Extensive drug resistant tuberculosis.

\section{Competing interests}

All authors declare that they have no competing interests.

\section{Authors' contributions}

SH conceived the idea of the study, prepared the study proposal, collected data in the field, performed the data analysis, and drafted the manuscript. GA and GM assisted with the preparation of the proposal and the interpretation of data, participated in data analysis, and critically reviewed the manuscript. BG participated in the proposal preparation, interpretation of data, and critical review of the manuscript. AM participated in the interpretation of data and critically reviewed the manuscript. MM and PS critically reviewed the proposal and the manuscript. All authors read and approved the final manuscript. All authors participated in critical appraisal and revision of the manuscript.

\section{Acknowledgements}

This paper was extracted from the MSc work of the first author, which was supported by Aklilu Lemma Institute of Pathobiology at Addis Ababa University, and funded by the US Agency for International Development (USAID) through the HEAL-TB (Help Ethiopia Address the Low TB Performance) Project, cooperative agreement 663-11-000002, managed by Management Sciences for Health. The views expressed in this publication are the responsibility of authors and do not necessarily reflect the views of USAID. The six co-authors supervised the first author for one year during his MSc work. The authors acknowledge the work of Barbara K. Timmons, PhD, in editing this article.

\section{Author details}

${ }^{1}$ College of Health Sciences, Adama Science and Technology University, P. O. Box 396, Adama, Ethiopia. ${ }^{2}$ Aklilu Lemma Institute of Pathobiology, Addis Ababa University, P. O. Box 1176, Addis Ababa, Ethiopia. ${ }^{3}$ Management Sciences for Health, HEAL-TB Project, P. O. Box 1157, Addis Ababa, Ethiopia. ${ }^{4}$ College of Health Sciences, School of Public Health, Addis Ababa University, P. O. Box 1176, Addis Ababa, Ethiopia. ${ }^{5}$ Management Sciences for Health, Arlington, VA, USA.

Received: 11 November 2012 Accepted: 22 August 2013 Published: 28 August 2013

\section{References}

1. World Health Organization (WHO): Drug-resistant tuberculosis now at record levels. 2010. http://www.who.int/mediacentre/news/releases/2010/drug_ resistant_tb_20100318/en/.

2. Loddenkemper R, Sagebiel D, Berndel A: Strategies against multidrugresistant tuberculosis. Eur Respir J 2002, 20:66-77.

3. World Health Organization (WHO): Multidrug and extensively drug-resistant TB (M/XDR-TB): 2010 global report on surveillance and response. Geneva: WHO; 2010. http://whqlibdoc.who.int/publications/2010/9789241599191_eng.pdf.

4. Federal Ministry of Health of Ethiopia (FMOH): Tuberculosis prevention and control programme: special issue for world TB day. 2011. 3:17-37.

5. Sharma SK, Mohan A: Multidrug-resistant tuberculosis: a menace that threatens to destabilize tuberculosis control. Chest 2006, 130:261-272.

6. Federal Ministry of Health of Ethiopia (FMOH): Participants' Manual: national comprehensive tuberculosis, leprosy and TB/HIV training for general health workers. Addis Ababa: FMOH; 2011

7. Federal Ministry of Health of Ethiopia (FMOH): Tuberculosis, leprosy and TB/HIV prevention and control program (manual). 4th edition. Addis Ababa: $\mathrm{FMOH} ; 2008$

8. Ormerod LP: Multidrug-resistant tuberculosis (MDR-TB): epidemiology, prevention and treatment. Br Med Bull 2005, 73-74:17-24. 
9. World Health Organization (WHO): Anti-tuberculosis drug resistance in the world: fourth global report. Geneva: WHO; 2008. WHO/HTM/TB/2008.394.

10. World Health Organization (WHO): WHO 2011 report on global tuberculosis control. Geneva: WHO; 2011.

11. Central Statistical Authority of Ethiopia (CSA): The 2007 population and housing census result of Ethiopia. Addis Ababa, Ethiopia: UNFPA; 2008.

12. Federal Ministry of Health (FMOH): Guideline for program and clinical management of drug resistant tuberculosis. 1st edition. Addis Ababa: $\mathrm{FMOH}_{\text {; }}$ 2009. http://www.etharc.org/resources/download/finish/66/367.

13. World Health Organization (WHO): Guidelines for treatment of tuberculosis. 4th edition. Geneva: WHO; 2010. WHO/HTM/TB 2009.420.

14. Daniel OJ, Oladapo OT, Alausa OK: Default from tuberculosis treatment programme in Sagamu, Nigeria. Niger J Med 2006, 15:63-67.

15. Andrews JR, Shah NS, Weissman D, Moll AP, Friedland G, et al: Predictors of multidrug- and extensively drug-resistant Tuberculosis in a high HIV Prevalence community. PLoS One 2010, 5(12):e15735. doi:10.1371/journal. pone.0015735.

16. Awofeso N: Anti-tuberculosis medication side-effects constitute major factor for poor adherence to tuberculosis treatment. Bull World Health Organ 2008, 86:161-240.

17. Obermeyer Z, Abbott-Klafter J, Murray CJ: Has the DOTS strategy improved case finding or treatment success? an empirical assessment. PLoS One 2008, 3(3):1721.

18. Tekle B, Mariam DH, Ali A: Defaulting from DOTS and its determinants in three districts of Arsi Zone in Ethiopia. Int J Tuberc Lung Dis 2002, 6:573-579.

19. Faustini A, Hall AJ, Perucci CA: Risk factors for multidrug resistant tuberculosis in Europe: a systematic review. Thorax 2006, 61:158-163.

20. Temple B, Ogwang S, Nabanija H, Kayes S, Nakubulwa S, Worodria W, Levin J, Joloba M, Okwera A, Eisenach K, Mugerwa R, Ellner J, López JE: Rate and amplification of drug resistance among previously-treated patients with tuberculosis in Kampala, Uganda. Clin Infect Dis 2008, 47:1126-1134.

21. Kanaya AM, Glidden DV, Chambers HF: Identifying pulmonary tuberculosis in patients with negative sputum smear results. Chest 2001, 120:349-355.

22. Ben Amor Y, Nemser B, Singh A, Sankin A, Schluger N: Under reported threat of multidrug-resistant tuberculosis in Africa. Emerg Infect Dis 2008, 14:1345-1352.

23. Akksilp S, Wattanaamornkiat W, Kittikraisak W, Nateniyom S, Rienthong S, Sirinak C, Ngamlert K, Mankatittham W, Sattayawuthipong W, Sumnapun S, Yamada N, Monkongdee P, Anuwatnonthakate A, Burapat C, Wells CD, Tappero JW, Varma JK: Multidrug-resistant TB and HIV in Thailand: overlapping, but not independently associated, risk factors. Southeast Asian J Trop Med Public Health 2009, 40:1000-1014.

24. Schwoebel V, Decludt D, de Benoist AC, Haeghebaert S, Torrea G, Vincent V, Grosset J: Multidrug resistant tuberculosis in France 1992-4: two casecontrol studies. BMJ 1998, 317:630-631.

25. Weyer K, Brand J, Lancaster J, Levin J, van der Walt M: Determinants of multidrug-resistant tuberculosis in South Africa: results from a national survey. S Afr Med J 2007, 97:1120-1128.

26. Alcorn K: HIV a major risk factor for MDR TB in Ukraine. AIDS map HIV \& AIDS news 2007; 2007. http://www.aidsmap.com.

doi:10.1186/1471-2458-13-782

Cite this article as: Hirpa et al.: Determinants of multidrug-resistant tuberculosis in patients who underwent first-line treatment in Addis Ababa: a case control study. BMC Public Health 2013 13:782.

\section{Submit your next manuscript to BioMed Central and take full advantage of:}

- Convenient online submission

- Thorough peer review

- No space constraints or color figure charges

- Immediate publication on acceptance

- Inclusion in PubMed, CAS, Scopus and Google Scholar

- Research which is freely available for redistribution 